\title{
En el nombre del niño \\ El interés superior del menor en la construcción \\ del rol de la Corte Suprema
}

Valentín Thury Cornejo

Recepción 11/06/13.

Aceptación: 06/10/2013

Resumen: El "interés superior del niño", principio consagrado en la Convención sobre los Derechos del Niño, se ha configurado como una pauta interpretativa y decisional de creciente uso por parte de la Corte Suprema de Justicia. A través del estudio de la jurisprudencia del Alto Tribunal durante el año 2012 analizamos aquí la forma en que ese principio es utilizado argumentativamente, para iluminar así el proceso de institucionalización que protagoniza la Corte Suprema. Las tensiones que se derivan de la construcción de legitimidad, como proceso político-institucional al que se aboca el tribunal, explican la diversa forma en que, según los contextos e intereses en juego, resuelve las controversias que involucran a los menores.

\section{Introducción}

De las normas de salvamento marítimo ("iNiños y mujeres primero!") a los slogans humanistas más difundidos ("los niños son el futuro") existe una conciencia cultural que da una cierta preeminencia a los intereses de los menores sobre los del resto de los actores sociales. Sea porque su vulnerabilidad obliga a mayores cuidados, por la promesa que su vida encierra o por la inocencia que se predica

* Investigador CONICET/Flacso Argentina, Profesor en la Maestría de Magistratura Judicial de la Universidad Austral. 
de esa existencia en formación, la civilización moderna ha tendido a resguardar a los niños de un modo especial. Esa protección ha asumido, en algunos casos, forma negativa, a través de la prohibición de determinadas conductas. Así, por ejemplo, se impide que los niños menores trabajen ${ }^{1}$. La contrapartida está en la obligación positiva del Estado de que los niños menores gocen de una escolaridad obligatoria $^{2}$. De este modo, nuestras sociedades han ido lidiando con las consecuencias negativas de la industrialización y han sentado las bases para el reconocimiento jurídico de un verdadero sujeto de derechos. Los ordenamientos nacionales avanzaron en ese terreno y, hace más de 20 años, la comunidad internacional adoptó la Convención sobre los Derechos del Niño como el documento que determina su status. Sus más de 50 artículos configuran un verdadero Bill of Rights de la niñez, cuyo criterio interpretativo se define por la búsqueda del "interés superior del niño". Este principio, consagrado en el artículo 3, se ha constituido en la piedra angular de este sistema de derechos pero esa condición no le ha quitado opacidad a la expresión. Su importancia corre pareja con su vaguedad.

Esta situación le genera a los intérpretes una doble sensación: una cierta angustia, derivada de la multiplicidad de posibilidades ante ellos abiertas y, al mismo tiempo, el poder que les da la discrecionalidad decisoria puesta en sus cabezas. Saber que es lo mejor para un niño es complejo para los jueces y, al mismo tiempo, puede transformarse en una fuente de poder decisional importante. Con un principio de estructura abierta y múltiples significados posibles, el juez parece quedar enteramente librado a su propia evaluación de la situación. En cambio, si ese principio se va concretando en una serie de definiciones y aplicaciones que limitan a los decisores futuros, el

1 Cf. Madeleine GreyBullard: "Child Labor Prohibitions Are Universal, Binding, and Obligatory Law: The Evolving State of Customary International Law Concerning the Unempowered Child Laborer", Houston Journal of International Law Vol. 24 (2001-2002), pp. 139ss.

2 Vid. por ejemplo, el art. 28.1.a) de la Convención sobre los Derechos del Niño, que obliga a los Estados firmantes a "implantar la enseñanza primaria obligatoria y gratuita para todos". 
En el nombre del niño. El interés superior del menor en la construcción ...

mismo dejará de ser una mera norma de habilitación discrecional para configurarse como un entramado de significados que limitan el margen actual de decisión. En el caso de reglas jurisprudenciales, podríamos hablar de una tarea de autolimitación: los jueces descartan interpretaciones posibles y así resignan margen de decisión en aras de una construcción jurídica que condicionará su actuación futura. Pero ¿por qué los jueces harían algo así? La respuesta, en el caso de los Tribunales Supremos, está en la tensión que gobierna sus decisiones y que se determina en base al concepto de legitimidad. Dicho de forma simple: los jueces son esencialmente actores jurídicos, encuentran su fuente de autoridad en el Derecho y se deslegitiman en la medida en que sus acciones son consideradas políticas. La creación y sujeción a reglas, por lo tanto, les otorga legitimidad mientras que los actos discrecionales, emparentados con la toma de decisiones propia del campo político, la cuestionan ${ }^{3}$.

Hay, pues, fuertes incentivos para la institucionalización de la actuación judicial pero también los hay para preservar facultades discrecionales, siempre y cuando éstas no sean vistas como facultades "políticas". En esto se basa gran parte de la retórica judicial: presentar lo político -en el sentido de toma de decisión discrecionalcomo inevitablemente jurídico -como algo impuesto por el Derecho, sobre lo que el intérprete no tiene margen de decisión- ${ }^{4}$. El manejo de la tensión Derecho-Política constituye institucionalmente al Tribunal, ya que éste elegirá así favorecer una u otra fuente de legitimación, de acuerdo, entre otras razones, con la lectura que realice del contexto en el que se mueve y las necesidades de la institución ${ }^{5}$. A mayor inestabilidad institucional, habrá mayores incentivos para no resignar cuotas de poder discrecionales, mientras que a mayor se-

${ }^{3}$ He desarrollado este argumento en Valentín Thury Cornejo: "La "nueva" Corte Suprema y sus estrategias de legitimación", El Derecho - Suplemento de Derecho Constitucional, 20 de febrero de 2008, pp. 15 y sigs.

4 Cf. Robert A. Ferguson: "The Judicial Opinion as Literary Genre", Yale Journal of Law \& Humanities, Vol. 2, N. 1 (1990).

5 Cf., por ejemplo, John P. Roche: "Judicial Self-Restraint", The American Political Science Review Vol. 49, No. 3 (Sep., 1955), pp. 762-772. 
guridad institucional, se abrirán mayores posibilidades de construir a futuro. A través de las decisiones jurisdiccionales concretas, los tribunales desarrollan una construcción institucional que se expresa en el modo en que interpretan y ven el derecho y, así, sus propias facultades para interpretarlo. Ello no necesariamente quiere significar que la construcción sea autoconsciente, pero sí que genera un modus operandi que deja sus huellas en cada una de sus sentencias.

El principio de interés superior del niño se muestra especialmente adecuado para dejar traslucir esta dinámica, pues su formulación jurídica vaga le otorga grandes márgenes de discrecionalidad al intérprete y deja espacio para que afloren las tensiones de la institucionalización. En este trabajo nos proponemos analizar la jurisprudencia de la Corte Suprema sobre este principio para ver cómo ilumina -y es iluminado por- su estrategia de construcción de identidad y consiguiente proceso de legitimación. Expandir el margen de decisión o autolimitarse, escuchar a los menores o presumir cuál es su verdadero interés, seguir las directivas legislativas o modificarlas en aras de principios superiores, todas ellas son decisiones que combinan argumentos de tipo jurídico con decisiones institucionales de tipo político. Muchas de ellas se esconden en las sutilezas de una retórica jurídica que se resguarda bajo la preeminencia moral del "interés superior del niño". Detectarlas nos obliga a agudizar la mirada y detenernos en los detalles de los casos estudiados. Esta necesidad hace que limitemos nuestro universo a los casos que la Corte Suprema resolvió en el último año, focalizándonos en las situaciones fácticas presentadas y en el modo en que el Tribunal argumenta y utiliza el interés superior del niño. Pero primero, a modo de pequeña contextualización teórica, daremos unos breves trazos normativos y dogmáticos acerca del principio que nos ayudarán a darle una dimensión adecuada a la tarea a la que la Corte Suprema se ha enfrentado. 
En el nombre del niño. El interés superior del menor en la construcción ...

\title{
II. Un principio en tensión
}

El principio en cuestión está consagrado en el artículo 3 de la Convención sobre los Derechos del Niño (en adelante, CDN):

\begin{abstract}
"En todas las medidas concernientes a los niños que tomen las instituciones públicas o privadas de bienestar social, los tribunales, las autoridades administrativas o los órganos legislativos, una consideración primordial a que se atenderá será el interés superior del niño".
\end{abstract}

Si bien el Comité de los Derechos del Niño -organismo previsto en los arts. 43 y siguientes de la Convención para examinar el cumplimiento de las obligaciones contraídas por los Estados Partes- no ha emitido una observación general respecto al principio del interés superior, sí lo ha hecho respecto del derecho del niño a ser escuchado -art. 12 de la $\mathrm{CDN}^{6}$-. Allí, luego de desgranar un análisis textual y contextual de la norma, el Comité vincula este derecho del niño con la búsqueda de su interés superior (art. 3) y afirma que:

“70. (...) El interés superior del niño es semejante a un derecho procesal que obliga a los Estados a introducir disposiciones en el proceso de adopción de medidas para garantizar que se tenga en consideración el interés superior del niño. La Convención obliga a los Estados Partes a garantizar que los responsables de adoptar esas medidas escuchen al niño conforme a lo estipulado en el artículo 12. Esta disposición es obligatoria ${ }^{7}$.

6 "Artículo 12. 1) Los Estados Partes garantizarán al niño que esté en condiciones de formarse un juicio propio el derecho de expresar su opinión libremente en todos los asuntos que afectan al niño, teniéndose debidamente en cuenta las opiniones del niño, en función de la edad y madurez del niño. 2) Con tal fin, se dará en particular al niño oportunidad de ser escuchado en todo procedimiento judicial o administrativo que afecte al niño, ya sea directamente o por medio de un representante o de un órgano apropiado, en consonancia con las normas de procedimiento de la ley nacional".

7 Comité de los Derechos del Niño: Observación General Nro 12: El derecho del niño a ser escuchado, $51^{\circ}$ Período de Sesiones, Ginebra, 25 de mayo a 12 de ju- 
En el ámbito nacional, la ley 26.061 de "Protección integral de los derechos de las niñas, niños y adolescentes" funciona como norma reglamentaria del CDN y brinda algunas pautas interpretativas para el derecho argentino:

"ARTICULO $3^{\circ}$ - INTERES SUPERIOR. A los efectos de la presente ley se entiende por interés superior de la niña, niño y adolescente la máxima satisfacción, integral y simultánea de los derechos y garantías reconocidos en esta ley.

Debiéndose respetar:

a) Su condición de sujeto de derecho;

b) El derecho de las niñas, niños y adolescentes a ser oídos y que su opinión sea tenida en cuenta;

c) El respeto al pleno desarrollo personal de sus derechos en su medio familiar, social y cultural;

d) Su edad, grado de madurez, capacidad de discernimiento y demás condiciones personales;

e) El equilibrio entre los derechos y garantías de las niñas, niños y adolescentes y las exigencias del bien común;

f) Su centro de vida. Se entiende por centro de vida el lugar donde las niñas, niños y adolescentes hubiesen transcurrido en condiciones legítimas la mayor parte de su existencia.

Este principio rige en materia de patria potestad, pautas a las que se ajustarán el ejercicio de la misma, filiación, restitución del niño, la niña o el adolescente, adopción, emancipación y toda circunstancia vinculada a las anteriores cualquiera sea el ámbito donde deba desempeñarse.

Cuando exista conflicto entre los derechos e intereses de las niñas, niños y adolescentes frente a otros derechos e intereses igualmente legítimos, prevalecerán los primeros."

La formulación del principio como la obligación de brindar una "consideración primordial" al "interés superior del niño" ha genera-

nio de 2009. Esta idea del Interés Superior del Niño como un derecho procesal se halla desarrollada en Jean Zermatten: "The Best Interests of the Child Principle: Literal Analysis and Function", International Journal of Children's Rights vol. 18 (2010), p. 485. 
En el nombre del niño. El interés superior del menor en la construcción ...

do numerosos problemas interpretativos. Las normas jurídicas que establecen prohibiciones -como la del trabajo infantil-son fácilmente discernibles en sus contornos interpretativos, al igual que las que establecen obligaciones concretas. Todos sabemos qué significa que un niño de 10 años no puede trabajar en una fábrica y sabemos que cuando nuestros hijos tienen 6 años deben comenzar la escuela primaria. En cambio, determinar qué significa el "interés superior del niño" en el contexto de la Convención sobre los Derechos del Niño es complejo y, más aún, lo es saber cuál es ese mejor interés en la situación concreta. Podríamos decir que esa situación deriva de su misma estructura jurídica, ya que como principio, su estructura es más abierta y porosa que la de la regla jurídica. Siguiendo a Alexy, su función es orientar la decisión: son "mandatos de optimización"8. Marca un norte, pero no lo define. En tanto indeterminado, su juridización depende de su concreción y, por tanto, de su delimitación técnica. Un concepto demasiado abierto pierde concreción jurídica, en la medida en que su contenido podría nutrirse de elementos no específicamente jurídicos. En ese caso, aducir el "mejor interés del niño" sería decidir en base a criterios extra-jurídicos (ético, tradicionales, de conveniencia, etc.) que luego son juridizados a partir de su cobertura retórica por el principio.

Esta situación ha generado no pocas críticas a su inclusión en la Convención sobre los Derechos del Niño. Algunos, por ejemplo, sostienen que genera más dudas que las que resuelve al ser indeterminado y de difícil aplicación ${ }^{9}$. Así, su vaguedad otorgaría un amplio poder al intérprete, ya que la generalidad del término utilizado le brinda una discrecionalidad de actuación casi ilimitada. De allí que

8 Cf. Robert Alexy: Teoría de los derechos fundamentales, Madrid: Centro de Estudios Constitucionales, 1993, pp. 86 y sigs.

9 Cf. Mónica Gonzalez Contró: Derechos Humanos de los Niños: Una propuesta de fundamentación, México: Universidad Nacional Autónoma de México, 2008, p. 404. Asimismo, otros autores resaltan el hecho de que los resultados de cualquier interpretación son indeterminados, o sea, no podemos saber ex ante cómo impactará la decisión en el futuro del niño (cf. David Archard \& Marit Skivenes: "Balancing a Child's BestInterests and a Child's Views", International Journal of Children's Rights vol. 17 (2009), p. 8) 
se plantee una tensión derivada de su calidad de concepto "juridizado": ¿es verdaderamente el interés superior del niño un concepto con contenido jurídico definido o es una mera delegación al juzgador para que ejerza su mejor criterio en la solución de los problemas que se le presentan a su decisión? La definición de su significado cobra así una relevancia enorme, ya que en la medida en que el principio se va concretando en su significado, de modo general -v.gr: a través de la fijación de reglas decisorias o procedimentales- el poder del intérprete decrece y su actuación se hace previsible. En este sentido, su limitación redunda en una mayor protección de los derechos del niño. En cambio, como afirma Garrido Alvarez, la latitud excesiva "anula por completo la idea de que los niños son sujetos de derechos al igual que los adultos y conspira contra la naturaleza de la función jurisdiccional en un estado de derecho que parece, a la luz de los derechos del niño, totalmente desprovista de legitimidad política (es un acto de autoridad en sentido neto)" 10 .

La clave de bóveda de interpretación del principio parece estar, en este sentido, en la consideración del niño como un verdadero sujeto de derechos. Si ello no fuera así, el interés superior podría interpretarse como una remisión a una directiva extra-jurídica que guiará la decisión a tomar por las personas de las que ellos dependen -padres o instituciones públicas-- En cambio, consagrado un catálogo de derechos en cabeza del menor es a él al que tal principio debe remitir. El rol de los adultos se mantiene en tanto el niño carece de plena autonomía, pero su ámbito de decisión está limitado por el carácter que el menor asume como sujeto moral y los derechos en su cabeza reconocidos. Miguel Cillero afirma, en este sentido, que "el interés superior del niño es la plena satisfacción de sus derechos" y estos son los consagrados específicamente en el texto de la Convención. Por lo tanto, el principio no es una directiva vacía, extra-jurídica, sino que refiere a una interpretación sistemática de la Convención sobre los Derechos

${ }^{10}$ Javier Garrido Alvarez: "El interés superior del niño y el razonamiento jurídico", Problema. Anuario de Filosofia y Teoría del Derecho-Universidad Nacional Autónoma de México- Nro 7 (2013), p. 123. 
En el nombre del niño. El interés superior del menor en la construcción ...

del Niño, que ayuda a resolver los eventuales conflictos entre derechos así como brinda una directiva concreta a las autoridades para la formulación de políticas públicas ${ }^{11}$. Diego Freedman sigue la línea de Cillero pero restringe la preeminencia interpretativa que otorga el interés superior del niño a lo que llama el "núcleo duro" de derechos del menor, compuesto por "el derecho a vida, a la nacionalidad y a la identidad, a la libertad de pensamiento y de conciencia, a la salud, a la educación, a un nivel de vida adecuado, a realizar las actividades propias de su edad (recreativas, culturales, etc.) y las garantías propias del derecho penal y del procesal penal"12.

Identificar el interés del menor en la situación concreta en que el derecho que le corresponde debe ser determinado -v.gr.: en la fijación de la tenencia o en un proceso de adopción-supone, en el sistema de la Convención, su participación directa. El art. 12 establece el derecho del niño a ser escuchado. Ahora bien, ¿qué sucede cuando ello no es posible, por ejemplo, porque se trata de un menor sin la madurez necesaria -v.gr: un bebé o un niño menor a dos años? En estos casos, la voluntad real del menor no puede ser considerada de forma efectiva. Entonces, ¿debe estarse a lo que sería su voluntad presunta, en condiciones hipotéticas? ${ }^{13}$ Igualmente, ¿debe considerarse su situación actual o los efectos de la decisión en el mediano largo plazo? ¿Cómo considerar la naturaleza progresiva del desarrollo del menor? ${ }^{14}$. Estas preguntas, a las que pueden sumarse muchas más, dan cuenta de la

${ }^{11}$ Miguel Cillero Bruñol: "El interés superior del niño en el marco de la Convención Internacional sobre los derechos del niño"en Emilio García Méndez \& MaryBeloff (comps.):Infancia, ley y democracia en América Latina. Análisis crítico del panorama legislativo en el marco de la Convención Internacional sobre los Derechos del Niño (1990-1998), Colombia: Ed. Temis/Depalma, Colombia, 1998, pp. 72 ss.

${ }^{12}$ Diego Freedman: "Funciones normativas del interés superior del niño", Jura Gentium. Rivista di filosofia del diritto internazionale e della politica globale, Vol. 2 (2005),p. 116.

${ }^{13}$ Cf. Paul Smeyers: "Child Rearing in the "Risk" Society: On The DiscourseOf Rights and the "Best Interests Of A Child", Educational Theory Vol. 60 Number 3 (2010), p. 277.

${ }^{14}$ Art. 5, Convención de los Derechos del Niño. 
dificultad de establecer a priori el interés superior del niño y el margen de discrecionalidad que su determinación otorga al intérprete. El desarrollo teórico y normativo que hemos tratado hasta aquí limita el ámbito decisional y brinda elementos para su control, discusión y evaluación, pero no puede -ni podría- suprimirlo. Será, pues, en la aplicación práctica en la que estas tensiones que aquí sucintamente describimos volverán a aparecer, muchas veces bajo nuevo ropaje y en contextos diferentes.

\section{Sentencias de la Corte Suprema de Justicia}

Según hemos visto, el año 2012 ha sido un año sumamente importante, desde el punto de vista jurisprudencial, para el interés superior del niño. De la decena de casos que resuelve la Corte Interamericana en un año, dos han tenido como eje central ese principio. Otro tanto ha sucedido con la Corte Suprema de Justicia de la República Argentina, donde el principio ha aparecido bajo formas y funciones variadas. La multiplicidad de casos tratados por la Corte Suprema durante el período pasado y parte del actual no supone una sistematicidad en el tratamiento del mismo, sino que simplemente demuestra la relevancia que el uso del principio tiene en la actualidad. No cabe duda, según veremos, que es una herramienta que el Alto Tribunal utiliza con frecuencia. Sin embargo, ¿cuál es la función que el mismo cumple? ¿Hay un desarrollo jurídico coherente? Contestar estas preguntas nos obliga a repasar, con detalle, los pronunciamientos en los que el interés superior del niño ha sido un elemento importante para la decisión. El repaso, en muchos casos, deberá concentrarse en el detalle ya que la generalidad del principio se concreta en la aplicación a la controversia concreta y ésta se define, no por grandes doctrinas, sino por el modo en que se ejecute la consigna en la que todos, a nivel dogmático, coinciden. Este hecho obliga a una reconstrucción teórica, cuyas líneas distan de estar claras a simple vista pero cuyas pautas intentaremos descifrar en lo que sigue.

Los casos que trataremos involucran temas tradicionales donde el interés superior del niño aparece necesariamente como criterio deci- 
En el nombre del niño. El interés superior del menor en la construcción ...

sorio principal (v.gr.: problemas de tenencia, adopción) y otros donde su aplicación se encuentra en el marco de la aplicación de otros principios y derechos respecto al cual ese interés concurre, sea para reforzarlo o limitarlo (v. gr.: vacunación obligatoria, derecho a la vivienda, aborto). Asimismo, el tratamiento del principio muchas veces es explícito y la Corte Suprema lo asume como la piedra angular de su razonamiento, mientras que otras veces resulta soslayado (v.gr: aborto en caso de violación). Respecto de la fuerza del principio, hay situaciones en las que el interés superior se reconoce en consonancia con las normas que lo reglamentan legalmente (v.gr.: discusión sobre la condición de parte del menor en juicio ${ }^{15}$ ) mientras que en otros lo pone en duda y "obliga" a la creatividad judicial (v.gr: adopción post-mortem). Estas distinciones responden a niveles de análisis que no siempre coinciden en una categoría común, sino que se entrecruzan y hacen compleja la clasificación. Lo intentaremos, sin embargo, a efectos de tener un orden en la exposición y avanzar en nuestra interpretación general de la jurisprudencia de la Corte Suprema.

Visto desde la perspectiva que en este trabajo proponemos -que conecta la construcción institucional del propio tribunal con la utilización del principio del interés superior del niño- hay dos aspectos que nos interesa especialmente destacar. El primero de ellos está compuesto por la utilización del principio como parte de una política activa del Tribunal en la promoción de determinados derechos. Esta ha sido una de las características esenciales de la política jurisprudencial de la Corte Suprema y el interés superior del niño ha jugado un papel en ella. Los tres casos en los que ello se demuestra son los de la vacunación obligatoria, el del derecho a la vivienda y del aborto en caso de violación. El segundo aspecto que nos interesa destacar es el uso del principio como fuente del Derecho, en su relación con el resto de la normativa de orden legal. El caso paradigmático que ilustra esta

${ }^{15}$ Por ejemplo, "Recurso de hecho por la Defensora Oficial de MSM en la contienda que sus padres estaban teniendo por su tenencia", CSJN, sentencia del 26 de junio de 2012. Al respecto, vid. Rodolfo G. Jáuregui: "La CSJN y un fallo que deja dudas a propósito de la intervención del abogado del niño", Revista de Derecho de Familia y de las Personas, Noviembre 2012, pp. 271/291. 
cuestión es el de la adopción post-mortem, en el que la Corte crea una nueva figura, no prevista en el ordenamiento, para resguardar lo que evalúa como el interés superior del niño. Estas cuestiones, si bien no son las únicas en las que la Corte Suprema utiliza el principio, nos permitirán ilustrar las diferentes variables que se hallan en juego en esta cuestión para luego conectarlas con la construcción del propio rol institucional que ensaya el tribunal.

\section{III.a. E1 ISN en la protección de derechos sustantivos del menor}

\section{III.a.1. Derecho a la salud (vacunación obligatoria)}

E1 día 2 de septiembre de 2009 nacía V.U. en parto domiciliario. Días después, su madre lo lleva al hospital Materno-Infantil de Mar del Plata para verificar el peso del niño y accede a la internación por prescripción médica pero se niega a cumplir con el protocolo oficial de vacunación por cuestionar la medicina científica y la institucionalidad del sistema de salud. Idas y vueltas mediante, la cuestión llega a la Corte Suprema encuadrada en el reclamo de los progenitores de que se respete su derecho de autonomía personal (art. $19 \mathrm{CN}$ ), en tanto la vacunación obligatoria obstaculizaría el plan de vida que han trazado para su familia. El Alto Tribunal, en fallo unánime, sostiene que ese principio encuentra límites en el derecho a la salud de la comunidad y en el interés superior del niño y que, por lo tanto, hay que vacunarlo ${ }^{16}$. Estos dos argumentos se presentan como interdependientes y se refuerzan uno al otro. ¿Tiene el grupo familiar un derecho a la privacidad? Sí, afirma la Corte Suprema pero en la medida en que ello no suponga daños a terceros. Por otra parte, ipuede esa privacidad ser decidida enteramente por los padres? Siempre y cuando no afecte el interés superior del niño, en este caso, por ejemplo, respecto a su salud. La clave de bóveda está entonces en la afirmación de que el incumplimiento de la vacunación obligatoria afecta la salud pública de la comunidad y del menor involucrado.

16 "N.N. o U.,V.s/protección y guarda de personas", sentencia del 12 de junio de 2012 (en adelante, U.V.). 
En el nombre del niño. El interés superior del menor en la construcción ...

La Corte comienza recordándonos la importancia del principio de autonomía consagrado en el artículo 19 de la $\mathrm{CN}$, como ámbito de protección de las decisiones fundamentales de la persona. Expresa en ese sentido que ese derecho a la privacidad "se extiende a situaciones en que alcanza a dos ó más personas que integran un núcleo familiar erigiéndose en el derecho a la privacidad de ese grupo" (art. 11.2 de la Convención Americana de DDHH). O sea, hay un principio de autodeterminación que excede a la persona individual y se extiende a la familia que ella, en conjunto con otras personas, ha formado. Sin embargo, esa autonomía tiene los límites que prescribe el artículo 19 y, en el caso de la decisión de no vacunación de su hijo, se afectaría el derecho a la salud de terceros al poner "en riesgo la salud de toda la comunidad y compromete(r) la eficacia del régimen de vacunaciones oficial, por lo que no puede considerarse como una de las acciones privadas del articulo 19 antes referido" 17.

Al separar este argumento del que luego va a hacer respecto de los intereses del niño específicamente involucrado, la Corte extiende el alcance de lo que va a decir. En efecto, esto vale para el menor UV pero también valdría -eventualmente- para un adulto que se encontrara en una situación semejante. En su razonamiento hay una cierta petición de principio, ya que supone que el daño a la salud se produciría porque la norma legal dispone la obligatoriedad de la vacunación, cuando justamente es esto lo que se pone en discusión. Ello es, los actores no ponen aquí en cuestión la obligatoriedad general de vacunación, sino que más bien le piden a la autoridad la posibilidad de una suerte de objeción de conciencia, tal como fue reconocida en el caso Portillo. Frente a ello, sostiene el Tribunal al final del considerando 22 que "la sumatoria de vacunas en todas ellas es la que previene las graves enfermedades que podrían contraerse si todos imitaran la actitud de los actores". Es necesario, parece entender, un principio de tolerancia cero ya que si no, cabría el riesgo de que nadie se vacunara y la salud pública se vería afectada.

${ }^{17}$ U.V., cons. 11. 
Mientras este primer argumento tiene como fundamento la privacidad del art. 19, expandida a un ámbito familiar, aquí esa privacidad se pone a prueba. En efecto, lo que dice la Corte Suprema es que el Estado tiene la obligación, en defensa del interés superior del niño (consagrado en los tratados internacionales incorporados a nuestra constitución), de intervenir en ese ámbito. Ya no está en juego, como en el primero, la línea divisoria autonomía individual-bien colectivo, sino la de autonomía de los padres vs el bien del menor. El argumento central a este respecto lo expresa la Corte Suprema en el considerando 22:

Que, en conclusión, de lo que se trata en el caso es de alcanzar la máxima certidumbre respecto del modo como mejor se satisface el interés superior del niño, lo que sin duda se traduce en optar por la mejor alternativa posible con el fin de asegurar el menor un presente cierto y contenedor que disminuya daños futuros irreversibles en lo que respecta a su salud. En este sentido, la no vacunación del menor lo expone el riesgo de contraer enfermedades, muchas de las cuales podrían prevenirse mediante el cumplimiento del plan nacional de vacunación. Asimismo, la circunstancia de que el resto de las personas sea vacunado reduce las posibilidades del niño de contraer enfermedades.

Para llegar a esta conclusión, la Corte hace un recorrido en el que enuncia este principio y destaca la tensión entre la definición de este interés por parte de la familia y la intervención estatal. Por ejemplo, en el considerando 19 cita textualmente el inciso a) del art. 14 de la ley 26061 (reglamentaria de la Convención de los Derechos del Niño). Allí se afirma que "los Organismos del Estado deben garantizar: a) El acceso a servicios de salud, respetando las pautas familiares y culturales reconocidas por la familia y la comunidad a la que pertenecen siempre que no constituyan peligro para su vida e integridad", para luego concluir con la cita de la parte final de ese artículo: "Las niñas, niños y adolescentes tienen derecho a la atención integral de su salud, a recibir la asistencia médica necesaria y a acceder en igualdad de oportunidades a los servicios y acciones de prevención, promoción, información, protección, diagnóstico precoz, tratamiento oportuno y recuperación 
En el nombre del niño. El interés superior del menor en la construcción ...

de la salud". Lo que hace la Corte Suprema, al fin de cuentas, es referir el interés superior del niño a la definición que el Estado hizo de la misma al determinar las normas de vacunación obligatoria. Hay aquí una asimilación entre la voluntad normativa y el interés superior del menor, que la Corte Suprema contrapone al interés de los padres ${ }^{18}$. La cuestión sin resolver, empero, es la de si la decisión de no vacunarlos puede ser caratulada como interés de los padres o estos la formulan en interés del menor, de acuerdo a las creencias que profesan. El enfrentamiento, que hábilmente la Corte disfraza, no es tanto entre los padres y el niño, sino entre ellos y el Estado -en cuanto legislador y juez-, respecto a quién tiene la capacidad para decidir sobre su bienestar.

\section{III.a.2. Derecho a la vivienda (Quisberth Castro)}

La causa trata sobre la situación de Sonia Quisberth Castro y su hijo, de 6 años, discapacitado. Quisberth Castro obtuvo un subsidio transitorio para las personas en "situación de calle", otorgado por el Gobierno de la Ciudad de Buenos Aires. Vencido el plazo máximo de vigencia de la ayuda -según la normativa que la creó-, accionó por su propio derecho y en representación de su hijo contra el Gobierno, defendido por la Defensoría General de la Ciudad. En primera y segunda instancia accedieron a su pedido y le prorrogaron, por medio de una medida cautelar, la ayuda otorgada. El GCABA apeló al Tribunal

${ }^{18}$ Que dentro de dicho marco, esta Corte Suprema ha sostenido que la atención principal al interés superior del niño apunta a dos finalidades básicas, cuales son la de constituirse en pauta de decisión ante un conflicto de intereses, y la de ser un criterio para la intervención institucional destinada a proteger al menor. El principio pues, proporciona un parámetro objetivo que permite resolver los problemas de los niños en el sentido de que la decisión se define por lo que resulta de mayor beneficio para ellos. De esta manera,frente a un presunto interés del adulto -que en el caso se vería reflejado por la voluntad de los padres expresada en el sentido de que no se le proporcionen al menor las vacunas que forman parte del plan nacional de vacunación por su elección de preferencia por los paradigmas del modelo homeopático y ayurvédico-, se prioriza el del niño (Fallos: 328:2870 y 331:2047). 
Superior de Justicia de la Ciudad de Buenos Aires y éste, remitiendo la doctrina de la causa Alba Quintana vs GCABA ${ }^{19}$, revocó la sentencia de Cámara ${ }^{20}$. E1 Tribunal porteño no analiza las particularidades del caso planteado -donde estaba en juego el derecho de un niño discapacitado- sino que se remite al precedente jurisprudencial donde, dos meses antes, había fijado posición sobre el programa de asistencia a las personas en situación de calle y su relación con el derecho a la vivienda. Sus líneas argumentales principales habían sido:

i. El contenido mínimo, básico e indisponible del derecho social a la vivienda reconocido constitucionalmente está dado por el abrigo que se otorgue a quienes no tengan un lugar donde vivir;

ii. El mencionado derecho social tiene un carácter progresivo cuyo alcance debe ser definido de modo gradual y general mediante leyes y reglamentos, siguiendo las prioridades fijadas constitucionalmente; corresponde a los poderes políticos definir y decidir respecto de las políticas públicas en materia de vivienda y no corresponde que los jueces creen soluciones o remedios judiciales más allá de las soluciones normativas previstas de modo general;

iii. Los subsidios temporales creados por vía reglamentaria, aunque sean insuficientes para atender de modo permanente la necesidad de vivienda, no son de por sí inconstitucionales en la medida en que en su asignación se respetan razonablemente las prioridades establecidas por el constituyente;

iv. La limitación de recursos presupuestarios que tiene el Estado para atender las diversas necesidades sociales justifica estos criterios de análisis y valoración de las políticas públicas en materia de derechos sociales ${ }^{21}$.

${ }^{19}$ STJ CABA: "Alba Quintana, Pablo c/ GCBA y otros s/ amparo (art. 14 CCABA) s/ recurso de inconstitucionalidad concedido", 12 de mayo de 2010, Expte. n 6754/09.

${ }^{20}$ STJ CABA: "Quisberth Castro, Sonia Yolanda c/ GCBA s/ amparo (art. 14 CCABA) s/ recurso de inconstitucionalidad concedido", 12 de julio de 2010, Expte. no 6769/09.

${ }^{21}$ Alfonso Santiago (h) e Isabel Zorraquín: "La tutela del derecho a la vivien- 
En el nombre del niño. El interés superior del menor en la construcción ...

El fallo del STJ había efectuado esa remisión en el entendimiento de que era el Tribunal inferior el que determinaría las condiciones fácticas para la aplicación de la doctrina. Por ese motivo -además de tratarse de una medida cautelar-el STJ de la Ciudad le había negado a la Defensoría la procedencia del Recurso Extraordinario, aspecto en el que coincidió con el dictamen de la Procuración General ${ }^{22}$. En este sentido, el interés de la Corte Suprema en entender en este caso despertó una gran expectativa, pues era la primera vez que el Alto Tribunal se pronunciaría sobre el derecho a la vivienda. Antes de hacerlo, celebró una audiencia pública informativa -15 de septiembre de 2011-, mecanismo reservado para casos que la Corte considera de gran relevancia pública ${ }^{23}$. Durante esa Audiencia, además de escucharse a la Defensoría General de la CABA, a su Procurador General y a la Ministra de Acción Social, tuvo relevancia especial la participación del Defensor Oficial ante la Corte, en representación del niño discapacitado $^{24}$. El enfoque que la Corte Suprema refleja en su sen-

da de las personas en situaciones de extrema vulnerabilidad y el control de razonabilidad de las políticas públicas habitacionales de la CABA", $E l$ Derecho Tomo 248 (2012), pp. 648.

22 "Q. C., Sonia Yolanda c/Gobierno de la Ciudad de Buenos Aires s/amparo", dictamen de la Procuradora Fiscal Laura Monti, de fecha 26 de mayo de 2011.

${ }^{23} \mathrm{El}$ mecanismo fue instaurado mediante Acordada 30/2007 y, desde ese momento, se han realizado 2 ó 3 Audiencias Públicas por año.

${ }^{24}$ El Defensor Oficial ante la Corte Suprema habló en representación del hijo de Quisberth Castro, Jordi o Jorge, de 6 años. El niño padece de una encefalopatía crónica, tiene un grave retraso cognitivo y defectos auditivos y visuales. Se halla sujeto a un proceso de rehabilitación constante, que incluye la provisión de medicación. Su alocución se concentró en describir la situación actual de la vivienda ( $3 \mathrm{~m} \times 3 \mathrm{~m}$, sin ventanas, en un primer piso por escalera, con un altillo al que el niño no puede acceder) y sostuvo que ésta es inadecuada para su situación. Jorge, afirmó, se halla en una situación de triple vulnerabilidad por su condición de niño, discapacitado y pobre y por ello, lo primero y principal es que la solución habitacional que se le provea debe ser permanente. Antes esta descripción, los ministros de la Corte trataron de conectar esta grave situación con los problemas más generales de vivienda que puedan tener otros habitantes de la ciudad, en el entendimiento de que los requisitos particulares de Jorge no son trasladables a todos los casos. 
tencia presenta el caso en una perspectiva diferente a como este había sido resuelto por el TSJ de la CABA: para el tribunal federal no es un caso típico de derecho a la vivienda sino que está condicionado por la especial situación de vulnerabilidad de la madre y del menor. Por esa razón, admitirá el recurso extraordinario ${ }^{25}$ y ordenará al Gobierno de la Ciudad que

"Garantice a la actora, aún en forma no definitiva, un alojamiento con condiciones edilicias adecuadas a la patología que presenta el niño, sin perjuicio de contemplar su inclusión en algún programa de vivienda en curso o futuro para la solución permanente de la situación de excepcional necesidad planteada."

La Corte Suprema elude las esperadas definiciones sobre las políticas de vivienda y los derechos sociales para concentrarse en las circunstancias especiales de este caso. El Tribunal elige un camino de no confrontación y prefiere no atarse las manos con una definición o interpretación del derecho a la vivienda. La CS hace así una serie de 3 consideraciones sobre los derechos sociales que creo que podrían ser suscriptas in totum por el STJ CABA: a) que las normas que consagran derechos sociales son operativas; $b$ ) que su operatividad es derivada, y c) que el Poder Judicial puede evaluar la razonabilidad del cumplimiento de las obligaciones a cargo del Estado. ¿Cuál es la dificultad de llevar esto a la práctica? Ella aparece cuando tenemos que definir cuál es el contenido del derecho a la vivienda consagrado en el ordenamiento. E1 STJ CABA hace un recorrido argumentativo y toma distintas fuentes interpretativas -principalmente, la OG 3 del PIDESC - para llegar a la definición de que el "refugio" configura un piso de ese derecho. La CS coincide en que hay una garantía mínima que se afecta cuando hay "una amenaza grave para la existencia misma de la persona". En este caso, dice, se dan estos requisitos "ya que

25 Dirá, en este sentido, que "el alcance que el a quo otorgó al derecho constitucional a la vivienda digna y la validez del programa de subsidios de la Ciudad ya no podrán ser discutidos ante la Cámara..." por lo que el gravamen, a pesar de tratarse de una medida cautelar, es irreparable. 
En el nombre del niño. El interés superior del menor en la construcción ...

es difícil imaginar un estado más desesperante: hay un niño discapacitado, con una madre en situación de calle"26. Es decir que mientras en una sentencia hay una objetivación de ese contenido mínimo -el refugio- en el fallo de la Corte hay simplemente un parámetro flexible: la amenaza para la existencia misma de la persona. O sea que, en el fondo, la CS no necesariamente revierte, en general, la doctrina de Alba Quintana sino que lo hace para esta situación especial de una mujer en situación de calle con un hijo discapacitado.

No es nuestro objetivo discutir aquí la doctrina que surge de la sentencia de la Corte Suprema respecto al derecho a la vivienda, sino poner de resalto la enorme influencia que la situación del menor tiene en la resolución del caso. Por ejemplo, al analizar las políticas del Gobierno dice que las dos opciones previstas para el caso QC no son aceptables desde el punto de vista constitucional: la entrega del subsidio no lo es porque "dicha asistencia no solo no constituye una solución definitiva al problema habitacional de este grupo familiar en situación de extrema vulnerabilidad sino que se limita a brindar un paliativo temporal" 27 , pero tampoco lo es el sistema de paradores, porque no tiene las condiciones edilicias mínimas para las necesidades del hijo de QC. La referencia directa al interés superior del niño -más allá de las largas referencias a los derechos de los menores y discapacitados al enunciar el marco normativo- se hace presente al tornar exigibles para el Estado la puesta en marcha de políticas públicas que den cuenta de la situación y ante las cuales no se pueden aducir excusas como la limitación presupuestaria:

"Que, como ya ha quedado expresamente de manifiesto, el caso en examen no solo es un simple supuesto de violación al derecho a una vivienda digna pues involucra a un niño discapacitado que no solo exige atención permanente sino que además vive con su madre en situación de calle. Entran aquí también en juego aspectos relativos a la situación en la sociedad de los discapacitados y la consideración primordial del in-

${ }^{26}$ Q. C., cons. 12, voto de mayoría.

${ }^{27}$ Q. C., cons. 13, voto de mayoría. 
terés del niño que la Convención sobre los Derechos del Niño impone a toda autoridad pública en los asuntos concernientes a ellos, que no es admisible que pueda resultar notoriamente dejado de lado por la demandada" 28 .

Más allá de las consideraciones estratégicas por las cuales la Corte Suprema podría haber elegido, en primer lugar, tratar este caso y, en segundo lugar, hacerlo de modo acotado, es notable la forma en la que el interés superior del niño informa su proceder. En efecto, sin hacer un gran desarrollo doctrinario -más bien se limita a una larga enumeración de normas aplicables-, este principio le sirve al Tribunal para darle carácter de caso excepcional por estar involucrado un menor discapacitado, en situación de extrema vulnerabilidad. Ante esta situación extrema, los razonamientos generales sobre la exigibilidad de los derechos sociales y su relación con las políticas públicas desarrolladas por los gobiernos ceden. En síntesis, esta es una sentencia que despertó grandes esperanzas respecto de los derechos sociales y terminó siendo un espaldarazo para los derechos de los niños.

\section{III.a.3. Autonomía individual vs Derecho a la vida (F.A.L.)}

Probablemente, el caso más resonante que la Corte Suprema haya tratado durante el año pasado haya sido "F., A. L. s/medida autosatisfactiva" del 13 de marzo de 2012, en el cual realizó una interpretación amplia del art. 86 inc. 2 del Código Penal respecto de los abortos no punibles y exhortó a las autoridades nacionales y provinciales a dictar una serie de medidas y protocolos tendientes a implementar dicha visión. Más aún que en el caso anterior de acceso a la vivienda, aquí el modo en que la Corte Suprema entiende en esta causa va a explicar su tratamiento del interés superior del niño -aquí, en realidad, su omisión. A.F., en representación de A.G. -su hija de 15 años- solicitó a la justicia de Chubut autorización para realizar un aborto, presuntamente producto de la violación de la niña por parte de O.C., su padrastro. 
En el nombre del niño. El interés superior del menor en la construcción ...

Luego de un paso por la justicia penal, la causa recayó en el fuero de familia, donde en primera y segunda instancia se rechazó el pedido. Sin embargo, el Superior Tribunal de Justicia revocó esas decisiones y autorizó la intervención. Esta sentencia fue recurrida en instancia extraordinaria por el Asesor General Subrogante de la Provincia de Chubut, en representación del nasciturus, y fue concedido, a pesar de que la práctica médica, en ese momento, ya había sido realizada. Sus argumentos referían a la afectación del derecho a la vida de la persona por nacer fundada en el texto mismo de la Constitución Nacional y varios de los tratados internacionales a ella incorporados, con particular énfasis en las normas de la Convención sobre los Derechos del Niño ${ }^{29}$.

El argumento para conceder el recurso fue la "gravedad institucional que presentaba el caso" 30 y allí comienzan las paradojas, porque a partir de la concesión, la controversia entre derechos constitucionales -autonomía de la solicitante para decidir la intervención y derecho a la vida de la persona por nacer- cede lugar a un ejercicio de interpretación jurídica, con carácter general, a cargo del Alto Tribunal. Para ello, la Corte Suprema se titula como "garante supremo de los derechos humanos" que debe resolver este caso por su posibilidad de repetición ${ }^{31}$. Evitar esta repetición pasa, en el criterio del Tribunal, por la correcta interpretación del art. 86 inc. 2 del Código Penal, que debe realizarse "a través de un análisis global

${ }^{29}$ Enumera el considerando 3 del caso F.A.L. al hacer el resumen de los antecedentes: “... Convención sobre los Derechos del Niño, Preámbulo: "El niño... necesita protección y cuidado especiales, incluso la debida protección legal, tanto antes como después del nacimiento", artículo $1^{\circ}$ : "Para los efectos de la presente Convención, se entiende por niño todo ser humano menor de dieciocho años de edad, salvo que, en virtud de la ley que le sea aplicable, haya alcanzado antes la mayoría de edad", y artículo 6 : "Los Estados Partes reconocen que todo niño tiene el derecho intrínseco a la vida".

${ }^{30}$ Puede consultarse una detallada crítica respecto de la concesión del recurso en Alberto F. Garay: "Aborto, recurso extraordinario y alcance de una decisión", Jurisprudencia Argentina- Suplemento de Jurisprudencia de la Corte Suprema de Justicia de la Nación 2012-II, pp. 62 y sigs.

${ }^{31}$ F.A.L., cons. 5. 
del plexo normativo fundamental involucrado" 32 , expresión que le permitiría justificar su incursión en el territorio vedado del derecho común $^{33}$. El voto de la mayoría se estructura así como un ejercicio de interpretación normativa, que comienza por rebatir los argumentos constitucionales invocados en el recurso para fundar una interpretación restringida del precepto, para seguir luego con las razones que sostienen la necesidad de una lectura amplia -por lo benévolade la norma penal. El conflicto entre los derechos se transforma: el del niño por nacer desaparece y los de la solicitante del aborto son opuestos al poder punitivo del Estado -titular de la acción penalbajo la forma del principio "pro homine", o sea, la que más derechos garantice frente al poder estatal ${ }^{34}$.

De este modo, el niño por nacer, que había sido el origen jurídico de la intervención de la Corte Suprema, desaparece por completo de la consideración jurídica. La sentencia no lo dice expresamente, pero cabría interpretar que sus derechos no resultan protegidos por la Convención sobre los Derechos del Niño en la medida en que las interpretaciones que de su texto se han hecho por los organismos oficiales no serían terminantes y la reserva hecha por laArgentina no sería tal:

... el artículo 2 de la ley 23849, en cuanto estipula que el artículo 1ro. de la Convención debe interpretarse en el sentido que se entiende por niño todo ser humano desde el momento de la concepción, no constituye una reserva que, en los términos del artículo 2 de la Convención de Viena sobre el Derecho de los Tratados, altere el alcance con que la Convención sobre los Derechos del Niño rige en los términos del artículo 75, inciso 22, de la Constitución Nacional. Esto porque, como surge del texto mismo de la ley, mientras que el Estado Argentino efectuó una reserva con relación a la aplicación del artículo 21 de

${ }^{32}$ F.A.L., cons. 8.

${ }^{33}$ Ampliar esta crítica en Valentín Thury Cornejo: "Atajos constitucionales, o la paradoja de saltarse vallas para derribarlas", Jurisprudencia Argentina- Suplemento de Jurisprudencia de la Corte Suprema de Justicia de la Nación 2012-II, pp. 89 y sigs. 
En el nombre del niño. El interés superior del menor en la construcción ...

la Convención, respecto del artículo $1^{\circ}$ se limitó a plasmar una declaración interpretativa ${ }^{35}$.

Hay muchos argumentos en la sentencia y pueden existir distintas visiones sobre su corrección y pertinencia, pero resulta claro que la Corte Suprema, en su voto de mayoría, no quiere plantear la cuestión del aborto no punible como una situación en la que dos derechos entran en conflicto. Al evitarlo, incumple justamente el principio que aquí estamos estudiando, que en su formulación normativa obliga "en todas las medidas concernientes a los niños que tomen las instituciones públicas" a darle "una consideración primordial" al interés superior del niño ${ }^{36}$. Como sabemos, ello no determina la solución a la que se llegará pero obliga a los jueces a tratar los temas y evaluar las consecuencias que ellos tendrán sobre los menores, obligación que aquí resulta soslayada por la peculiar estructura argumentativa que asume la sentencia. Solamente Argibay reconoce explícitamente que se está ante un "severo conflicto de intereses" entre el derecho a la vida de la persona por nacer y la situación de la niña de 15 años embarazada a consecuencia de una violación de la que ha sido víctima ${ }^{37}$, conflicto que ella entiende razonablemente ponderado por la norma penal en su interpretación amplia.

\section{III.b. E1 ISN y el orden jurídico establecido}

En los tres casos que acabamos de revisar, la Corte Suprema actúa como un verdadero tribunal constitucional, ello es, interpretando la Norma Fundamental para evaluar los conflictos de derechos planteados y determinar su respectivo alcance. En ese sentido, su determinación se separa de lo anteriormente decidido por las instancias inferiores y las sentencias se presentan como una respuesta a la pregunta: ¿tienen estos niños derecho a la salud, la vivienda, la vida o la autono-

${ }^{35}$ F.A.L., cons. 13 in fine.

36 Art. 3.1. Convención sobre los Derechos del Niño.

${ }^{37}$ F.A.L., voto de Argibay, cons. 13. 
mía personal? Para responderla, la Corte Suprema utiliza el principio del interés superior del niño (o no lo hace, cuando debería). En uno u otro caso, este está relacionado con un derecho concreto y su introducción (o falta de ella) asume la función de criterio interpretativo. La sentencia a la que ahora nos vamos a referir, en cambio, nos propone a una Corte cuyo interés principal va a ser la revisión de lo actuado por las instancias inferiores, para decidir un caso concreto. El foco, aquí, va a estar dirigido al modo en que los tribunales deberían haber decidido las causas y no tanto a sentar una doctrina sustantiva sobre la interpretación del ordenamiento material. En este sentido, la sentencia asume una posición asimilable a la de la Corte Interamericana en el caso Fornerón, donde aquella discutió la aplicación del principio del interés superior del niño por los tribunales de la Provincia de Entre Ríos. Esta relación es doblemente interesante, porque nuestro Alto Tribunal cita expresamente esa sentencia como motivadora de su decisión, generando un diálogo jurisprudencial que, adelantamos, se presenta como complejo.

\section{III.b.i. La adopción post-mortem de A. en la provincia de Entre Ríos}

María Inés Martínez del Sel vivió una vida signada por las tragedias. Viuda joven por un accidente en parapente de su marido, uno de los herederos de la farmacéutica Roemmers, años después tiene un accidente en avión cruzando el Río de la Plata del que se salva milagrosamente para seis meses después morir en un accidente de tránsito, volviendo de Mundo Marino por la ruta 11. Corría el año 2006 y apenas unos días antes del accidente fatal, había aceptado la guarda preadoptiva de A. a quien había tenido consigo desde fines del 2003. Muerta María Inés, ¿qué pasará con A.? Esta es la pregunta que se hace la Defensora de Menores de Gualeguaychú -donde tramitaba la guardia-y decide asumir la representación promiscua de A. y solicitar la adopción plena, post-mortem, en cabeza de la fallecida. La jueza de primera instancia le dice que sí, se la otorgan y comienzan la sucesión. Los padres de María Inés no están de acuerdo y accionan judicialmente, afirmando que todo lo actuado es nulo. La Cámara le da la razón 
En el nombre del niño. El interés superior del menor en la construcción ...

a la 1ra instancia, el Tribunal Supremo de Justicia de Entre Ríos a los padres $^{38}$ y la Corte, finalmente, bendice la primera solución ${ }^{39}$. Todos aducen actuar teniendo en miras "el interés superior del Niño", tal como lo prescribe la Convención de los Derechos del Niño, lo cual plantea un interesante conflicto de visiones sobre la función judicial y el modo de aplicar ese principio.

El Tribunal Superior de Justicia de Entre Ríos enuncia de modo muy preciso cuáles son los límites jurídicos que la adopción post-mortem dispuesta tuvo que derribar para constituirse como tal. Sintéticamente expuestos:

1. El juicio de adopción no se había iniciado y al morir MIMdS la guarda preadoptiva se extingue, no estando dadas las condiciones previstas por el Código Civil para que la adopción se produzca.

2. La Defensora de Menores no tiene legitimación activa para pedir la adopción. Según el art. 311 el proceso de adopción se inicia "a instancias del adoptante" y, ésta, en este caso estaba muerta por lo cual no podía expresar su voluntad en ese sentido. Esa expresión, dice el TSJ con cita de profusa doctrina civil, es fundamental a los efectos de la adopción.

3. El proceso de guardia preadoptiva y el de adopción están relacionados pero el primero no supone al segundo, ni lo define. Esa es la razón por la cual la normativa incluyó a los dos como pasos necesarios para la adopción. Ergo, el hecho de que se hubiera definido la guardia preadoptiva no significa una expresión de voluntad válida respecto del segundo proceso.

4. La adopción tiene, en el derecho argentino, unos fines legales que no deben ser desconocidos. Estos se refieren "a un compromiso legal y moral de contención, cuidado y formación del menor con las correlativas responsabilidades que el ejercicio de la patria potestad implica" y que, ante la muerte de MIMdS eran de imposible cumplimiento.

${ }^{38}$ Superior Tribunal de Justicia de la Provincia de Entre Ríos, Sala II en lo Civil y Comercial: "M. DEL S., R. y otra", 31 de agosto de 2010.

${ }^{39}$ CSJN, "M. d. S., R. y otra s/ ordinario s/nulidad de sentencia e impugnación declaratoria de herederos", 26 de septiembre de 2012. 
Valentín Thury Cornejo

5. Por esas razones, el acto de adopción dispuesto por el Juzgado se agotaba en el mismo momento de su constitución, no brindando una solución real para la situación del menor A.

6. En las propias palabras del Tribunal Superior entrerriano:

"Resulta manifiestamente paradojal, incongruente y contrario a la finalidad del instituto, la solución dada al caso en cuanto, en la lógica y estructura sentencial, el acto constitutivo de la filiación - sentencia judicial que otorga la adopción a instancia del Ministerio Público - implica simultáneamente la puesta del menor en situación de desamparo y en estado de adoptabilidad en tanto el régimen legal regulatorio de la adopción específicamente prevé como respuesta idónea para el supuesto de su extinción - en el caso, por orfandad, por muerte de la única adoptante - la adopción sucesiva o sea, el otorgamiento de una segunda adopción (art. 312, 1er. párr. in fine, del Código Civil) no siguiendo en lo puntual los lineamientos del Código Civil para el caso de la filiación biológica que prevé y regula el instituto de la tutela - legal, dativa o testamentaria- (arts. 377, 383, 389, 392 у сc)."

En pocas palabras, el TSJ de Entre Ríos dice que la justicia provincial de grado ha intentado dibujar un círculo cuadrado y no se comprende muy bien cómo ello puede beneficiar la situación del menor A. En concreto, afirma que la adopción dispuesta no puede cumplir con los fines previstos en la legislación argentina respecto de ella. Ergo, el "interés superior del niño" debe evaluarse de acuerdo con el ordenamiento en el que el mismo se desarrolla y en el marco de sus límites institucionales, ya que son ellos los que le dan contenido. Nos hemos extendido en esta reseña, porque entendemos que en la resolución de este caso es más importante una determinada sensibilidad respecto de las funciones del juez que una discusión jurídica sobre las normas en juego. Dicho en otras palabras: ¿el juez debe ser creativo y trascender las normas concretas en su búsqueda del interés superior del niño? $\mathrm{O}$, por el contrario, ¿debe atenerse a ellas y considerarlas como apreciaciones generales de ese interés superior? En la primera versión, el juez 
En el nombre del niño. El interés superior del menor en la construcción ...

no tiene casi límites a su creatividad, en la segunda, sí. Este enfoque se va a entender mejor cuando analicemos las vallas que debe saltar la Corte Suprema para entender en este caso.

\section{III.b.ii. Dificultades para la Corte Suprema}

Este caso llega a la Corte Suprema de un modo sumamente irregular, y la Procuración General ${ }^{40}$ (y el tribunal al adherir a su dictamen) van a utilizar el interés superior del niño como eximentes de una serie de requisitos formales y sustanciales que impedirían la vía extraordinaria. Por ejemplo, la queja fue presentada fuera de plazo pero Lorenzetti, Highton, Maqueda y Fayt ${ }^{41}$ consideran que "dar prioridad al principio de perentoriedad de los plazos no solo resultaría contrario a razones de justicia y equidad que median en el caso, sino que además significaría frustrar los derechos que se encuentran en juego mediante una decisión excesivamente rigurosa" 42 . A esta excepción, de por sí notable y extraordinaria, se le suma una interpretación muy flexible dela jurisdicción de la Corte Suprema respecto de las cuestiones de derecho público local y de derecho común. Estas materias, como sabemos, son tradicionalmente ajenas a la instancia extraordinaria pero el Tribunal encontrará aquí razones para decidir la causa, razones que se suman a la interpretación sustantiva del Código Civil en el sentido de la posibilidad de la adopción post-mortem.

Una de las principales controversias que se habían producido en esta causa se refería a la legitimidad del Ministerio Público entrerriano para solicitar la adopción, ya que la acción de adopción sería de ejercicio exclusivo y excluyente del pretenso adoptante ${ }^{43}$. Se mezclan aquí las normas de fondo -Código Civil-y las normas locales que reglamentan la figura y competencias del Ministerio Público, lo cual haría que tanto por ser materia de derecho común y de derecho pú-

${ }^{40}$ Dictamen del 24 de abril de 2012.

${ }^{41}$ Son los únicos firmantes de la sentencia, ya que Argibay, Petracchi y Zaffaroni no participan de la misma.

42 "M. d. S., R.", considerando 15.

${ }^{43}$ Conforme art. 311 Cód. Civil. 
blico local, su conocimiento le estaría vedado a la Corte Suprema. En contra de esta intuición, la Procuración General entiende aplicable la doctrina del Tribunal respecto a las funciones del Ministerio Público Federal, basada en la similitud de la norma provincial que rige su competencia y la nacional. En concreto, afirmará que "el tribunal local se ha apartado inmotivadamente de la doctrina de esa Corte" al negarle la atribución que tiene "de entablar cuantas acciones hagan a la defensa de los intereses de los menores de edad". El derecho público federal se impone así sobre el local, en una extensión de la doctrina de la Corte Suprema y de la obligatoriedad de los tribunales provinciales de seguirla.

Esto se relaciona, a su vez, con la sustancia de la decisión a tomar. Estamos, claramente, ante una cuestión de derecho común, la interpretación de las normas del Código Civil referentes a la adopción. De hecho, el interés superior del niño ha sido incorporado como uno de los criterios que debe seguir el juez en sus decisiones ${ }^{44}$. O sea, que ese principio se encuentra incorporado ya a la legislación común e informa el ordenamiento todo. Sin embargo, la Procuración General -a quien la Corte sigue en su fallo- entiende que "el tribunal superior de la causa ha incurrido en una apreciación rigurosamente literal de los textos legales aplicables, en desmedro del mejor interés del niño consagrado en los arts. 3.1 y 21 de la Convención sobre los Derechos del Niño (en adelante, $\mathrm{CDN}$ ), y con la consecuente frustración de los derechos amparados por los arts. 17, 18 y 19 de la Constitución Nacional. Dicha circunstancia configura, a mi ver, justificación bastante para autorizar la apertura de esta instancia excepcional". En síntesis, nos encontraríamos aquí ante un "super-principio" que habilita a crear formas jurídicas no previstas por la normativa (adopción post-mortem), a agrandar la jurisdicción extraordinaria de la Corte y a eximir a los recurrentes de requisitos -que pasan a considerarse de excesiva rigidez- como los plazos procesales. 
En el nombre del niño. El interés superior del menor en la construcción ...

\section{III.b.iii. Una apuesta por la creatividad judicial}

El fallo de la CS se compone de tres partes: un relato de los hechos que complementa al efectuado en el dictamen de la Procuración General, su adhesión a lo sugerido por aquél y una serie de consideraciones adicionales. Estas abordan dos aspectos destacables. E1 primero de ellos refiere a la entonces muy reciente sentencia de la Corte Interamericana en el caso "Fornerón" 45 . Esta es citada en los considerandos 9 y 10 del fallo, para destacar los principios generales del "interés superior del niño", ello es, la necesidad de que sea un criterio determinante en la decisión a tomar, que el mismo se basa en la dignidad misma del ser humano y que su determinación debe hacerse de acuerdo a las circunstancias concretas del caso. Asimismo, menciona el derecho a la identidad del niño que la Corte Interamericana desarrolló allí. La referencia de la Corte Suprema al caso Fornerón plantea la cuestión acerca del seguimiento de la Corte Suprema a los dictados de ese tribunal, máxime a la luz de la reciente doctrina del control de convencionalidad ${ }^{46}$. En este sentido, su mención resulta doblemente paradojal. En un primer sentido, podríamos decir que más notorio, la lectura que hace la Corte Suprema se mantiene en los puntos generales que acabamos de resumir pero no recoge ninguno de los criterios concretos mediante los cuales ese Tribunal evaluó la actuación judicial en aquel caso. Baste recordar aquí su determinación de que el interés superior del niño resulta protegido por la "observancia de las disposiciones legales" y que no puede invocarse ese interés "para legitimar la inobservancia de requisitos legales" 47 .

${ }^{45}$ Corte Interamericana de Derechos Humanos: "Caso Forneron e Hija vs. Argentina", sentencia de 27 de Abril de 2012 (Fondo, Reparaciones y Costas).

${ }^{46}$ Cf. CIADH: "Caso Almonacid Arellano y otros vs. Chile", Sentencia del 26 de septiembre de 2006, Serie C, Nro. 154.

47 "Este Tribunal considera que la observancia de las disposiciones legales y la diligencia en los procedimientos judiciales son elementos fundamentales para proteger el interés superior del niño. Por otra parte, no puede invocarse el interés superior del niño para legitimar la inobservancia de requisitos legales, 
La Corte Interamericana encuentra en las normas legales y procedimentales una aplicación concreta de ese principio y cree necesario limitar el poder de los jueces de interpretarlos en forma demasiado flexible, tal como había resultado en aquel caso. En este sentido también, la referencia de la Corte Suprema es paradojal, porque recordemos que se trataba allí de un proceso de adopción, en la misma provincia de Entre Ríos, donde el señor Fornerón se había visto despojado de la relación con su hija por la decisión de la madre biológica de darla en adopción ${ }^{48}$. La CIADH había decretado el pésimo funcionamiento de la justicia entrerriana y había ordenado que Fornerón pueda reestablecer relaciones y ver a su hija. Sin embargo, a poco que ahondemos, podrían hacernos estas otras preguntas: ¿resulta razonable delegar tantos poderes discrecionales en una justicia que ha producido un caso como Fornerón? Las funciones creativas que el modo en que la PG y la Corte proponen que se interprete el interés superior del niño supone una alta confiabilidad en la actuación judicial. En cambio, la postura del TSJ de apegarse a las normas, supone un control más estricto de su actuación. Si estamos atentos a lo que significó el caso citado, ¿es correcta (más allá de las consideraciones jurídicas) la postura de la Corte Suprema como política judicial?

E1 segundo aspecto destacable de la argumentación de la Corte Suprema hace referencia a su entendimiento y descripción del principio de interés superior del niño. Repite primero su fórmula tradicional: "frente a un presunto interés del adulto, se prioriza el del niño", regla que se comprende en el caso de intereses contrapuestos. No parece ser esa la situación, ya que aquí no estamos ante la discusión de

la demora o errores en los procedimientos judiciales." (Fornerón, par. 105)

${ }^{48}$ Se podría avanzar más en el paralelismo entre los dos casos. Por ejemplo, la tenencia inicial de A. había sido otorgada a MIMdS por una escritura pública, un par de años antes de que se iniciara el proceso judicial de guardia pre-adoptiva. En este caso, al padre de la madre biológica -que era entonces menor- le negaron participación en ese proceso (a pesar de que su consentimiento era requerido, se lo había declarado ausente luego de citarlo por edictos). Ello quiere decir que las irregularidades procedimentales se adivinan en este caso, como también la sombra de la compra-venta de niños se proyecta sobre ambos. 
En el nombre del niño. El interés superior del menor en la construcción ...

una vocación hereditaria -aunque, obviamente, esté involucrada, no es el objeto del proceso-, sino que se está evaluando la legitimidad de la adopción dispuesta por la justicia de grado. Reducir esa cuestión compleja a un conflicto entre intereses distintos parece, al menos, fuera de contexto. Continúa la Corte y afirma:

\begin{abstract}
Asimismo, se ha señalado que al considerar y hacer prevalecer por sobre todos los intereses en juego, el del sujeto más vulnerable y necesitado de protección, los tribunales deben ser sumamente cautos en modificar situaciones de hecho respecto de personas menores de edad y mantener, en consecuencia, aquellas condiciones de equilibrio que aparecen como más estables, evitando así nuevos conflictos cuyas consecuencias resultan impredecibles (conf. Fallos: 328:2870 y 331:147).
\end{abstract}

No resulta claro cuál sería la situación de estabilidad que habría que preservar, dada la muerte de MIMdS. La muerte es un hecho irreversible. Si tenemos que extrañar al que se va, no nos queda otro remedio que hacerlo. ¿En qué morigera esa situación la adopción post-mortem? ¿No era posible, acaso, darle la tutela a la hermana-como de hecho se hizo- sin que se declarara la adopción? El marco interpretativo que utiliza la CS parece estar centrado en unos hechos distintos de los de esta causa. Dice, por ejemplo, en el considerando 12 que la aplicación literal y dogmática del TSJ produjo como consecuencia "la desvinculación del menor A. respecto de quien en vida lo cuidó en sus primeros años de existencia generando un vínculo materno-filial, lo insertó en su grupo familiar y expresó su voluntad adoptiva no solo al promover y obtener su guarda sino también al designarlo públicamente como "mi hijo" en uno de sus testamentos ológrafos". Esa desvinculación la produjo la muerte de María Inés, no la interpretación dogmática de un tribunal. ¿Es que acaso la adopción plena remedia, por sí misma, algunas de las cuestiones que enuncia aquí la Corte Suprema? Se habla del interés del menor y, paradójicamente, se termina citando el interés del adoptante que expresó su voluntad en el testamento. ¿Qué relevancia tiene ese hecho respecto del interés actual de A y de su futuro, una vez muerta MIMdS? 
La sentencia no nos brinda respuestas a estas preguntas, solamente nos deja unos principios que invitan a la creatividad judicial y van en sentido contrario a los dictados de Fornerón. Dice, por ejemplo:

Que, en tal sentido, se ha resuelto que cuando se trata de resguardar el interés superior del niño, atañe a los jueces buscar soluciones que se avengan con la urgencia y la naturaleza de las pretensiones, encauzar los tramites por vías expeditivas y evitar que el rigor de las formas pueda conducir a la frustración de derechos que cuentan con particular tutela constitucional (conf. Fallos: 324:122 y 327:2413 y 5210)"49.

Que por último, en cuestiones en que se ven involucrados los derechos de los menores, esta Corte Suprema ha afirmado que resulta totalmente desvirtuada la misión específica de los tribuna1es especializados en temas de familia si estos se limitan a decidir problemas humanos mediante la aplicación de una suerte de fórmulas o modelos prefijados, desentendiéndose de las circunstancias de1 caso que la ley les manda concretamente valorar (conf. Fallos: 323:91; 328:2870; 331:147 y 2047)"50.

\section{III.b.iv. Conclusión}

Un caso verdaderamente difícil, con una posible discusión muy interesante sobre los fines de la adopción y su régimen, que esta sentencia evita. En su lugar, se queda con una coartada retórica (el interés superior del niño) que le permite pontificar y eludir los términos reales de la disputa. Al hacerlo, debe saltar varias vallas "insalvables": la del derecho involucrado es una, la de los requisitos procedimentales de su intervención es otra. A ella se le suma, de un modo más sutil, la de su fidelidad a los dictados de la Corte Interamericana. La Corte Suprema salta estos obstáculos, optando por la versión del interés superior del niño que más poder les otorga a los jueces, opción que, en el marco de 
En el nombre del niño. El interés superior del menor en la construcción ...

los problemas derivados de la compra-venta de niños, aparece como una opción cuanto menos peligrosa. Su relación con la norma escrita aparece así en conflicto: ¿hasta dónde hay interpretación flexible? ¿Cuándo comienza a tergiversarse un sistema? Más aún, ¿cuáles son las consecuencias a mediano plazo de esta creatividad judicial? La potencia retórica del "interés superior del niño" juega a favor de la Corte ${ }^{51}$, que erigiéndose en su máximo intérprete y otorgándole al principio poderes que trascienden el ordenamiento establecido, elude todos y cada uno de los condicionamientos que se oponen a su libre interpretación.

\section{Interés Superior del Niño y construcción institucional}

El recorrido que hemos hecho para revisar la jurisprudencia de la Corte Suprema de Justicia de la Nación en materia de interés superior del niño nos habla, por sí solo, de la relevancia que el mismo tiene en las sentencias del Tribunal. Desde una mera visión cuantitativa, podríamos afirmar el desarrollo que el mismo ha tenido y la importancia que el Tribunal ha dado a la protección de los derechos del menor. Sin embargo, al realizar un análisis más detenido de los casos en que el mismo ha sido aplicado, luces y sombras comienzan a aparecer pues la aplicación que ha hecho la Corte Suprema dista de responder a un único parámetro. Ello puede explicarse por distintas razones, por ejemplo, la compleja organización interna del tribunal, que puede dar la sensación de que muchas voces hablan a través suyo ${ }^{52}$. Las dife-

${ }^{51}$ En términos retóricos, podríamos afirmar que la Corte Suprema hace jugar al principio como un "God-term", o sea, una palabra que tiene un significado impreciso pero una potencia retórica que legitima las decisiones tomadas en su nombre (cf. Kenneth Burke: A grammar of motives, New York: Prentice Hall, 1952, p. 355).

${ }^{52}$ Cf. Héctor E. Sabelli: "Cómo trabaja la Corte", Jurisprudencia Argentina, Suplemento (I), 2007, pp. 3-12; Leticia Barrera: La Corte Suprema en escena. Una etnografia del mundo judicial, Buenos Aires: Siglo XXI Editores, 2012, especialmente capítulo 4, y Leticia Barrera: "La circulación de expedientes y las formas de los expertos legales: agencia y sujeto en la Corte Suprema ar- 
rencias podrían rastrearse, por lo tanto, en el particular trámite que cada expediente siguió ${ }^{53}$. La teoría que guía este trabajo, sin embargo, sostiene que debajo de esas diferencias aflora una lógica institucional que puede explicar las principales notas que caracterizan esta jurisprudencia. La Corte -aunque no exclusivamente- habla a través de sus sentencias. Quizás no lo hace siempre de modo explícito, pero a través de los casos que decide abordar, del modo en que lo hace y cómo argumenta sus decisiones se pueden rastrear las huellas de un determinado modelo judicial. Este se encuentra en germen en la norma constitucional, que instituye la Corte Suprema, define su lugar en el esquema de poderes y dota de garantías a sus miembros. Pero a partir de ese diseño básico va a ser el propio tribunal el que va a proseguir su tarea de institucionalización, eligiendo una identidad, dándose normas de procedimiento, adhiriendo a valores específicos, relacionándose con otros actores. Si entendemos por institución las reglas del juego en una sociedad o una organización, o sea, "las restricciones u obligaciones creados por los seres humanos que le dan forma a la interacción humana" 54 , la institucionalización va a ser el proceso de creación de esas normas ${ }^{55}$ y en el caso de la Corte Suprema, va a depender de su propia actuación.

Sostiene McGuire en su estudio sobre la Corte Suprema de EE.UU. que tres son los principales indicadores para medir el grado de ins-

gentina", Revista Jurídica de la Universidad de Palermo, Año 10 Nro. 1 (2009), pp. 221-240.

${ }^{53}$ ¿Fue un proyecto de Secretaría de Corte? ¿O surgió de una vocalía de Ministro? ¿Es un caso relevante al que los Ministros prestaron consideración especial o fue considerado un asunto de trámite? ¿Fue un recurso extraordinario concedido o hubo que interponer queja? ¿Es un caso de arbitrariedad de sentencia? Esas entre otras muchas condicionan el trámite de un expediente en la Corte Suprema, los funcionarios que intervienen y, consecuentemente, los resultados, sin que funcione siempre un sistema que homogenice los resultados obtenidos.

${ }^{54}$ Douglas North: Instituciones, cambio institucional y desempeño económico, México: Fondo de Cultura Económica, 1995, p. 3

${ }^{55}$ Cf. Samuel N. Eisenstadt: "Institutionalization and Change", American Sociological Review Vol. 29 Nro. 3 (1964), p. 235. 
En el nombre del niño. El interés superior del menor en la construcción ...

titucionalización de los actores públicos: diferenciación, autonomía y durabilidad ${ }^{56}$. El primero de ellos refiere a la diferenciación de su entorno, ello es, a su capacidad para tener un rol bien definido en el entorno de poderes en los que se mueve, llevando a cabo tareas únicas no cumplidas por los otros actores. En el caso de la Corte Suprema, ella debe distinguirse de las ramas políticas - presentándose como un órgano jurídico, aplicador del Derecho- y, asimismo, del resto de los miembros del Poder Judicial -asumiendo su calidad de "cabeza del Poder Judicial"-. La autonomía, por su parte, remite a su capacidad de acción sin obedecer a los otros actores. Este indicador es el que comúnmente identificamos con la noción de "independencia" y es el que se encuentra mayormente garantizado en el texto constitucional, a través de una serie de garantías -inamovilidad, intangibilidad remuneratoria, etc.-. En lo funcional, esa autonomía se manifiesta en la posibilidad de construir su propia agenda de actuación. Por último, la durabilidad es definida por McGuire como "la habilidad para persistir y adaptarse al cambio" 57 . En el caso de la Corte Suprema, ello significa adquirir las características de un actor estable, que se mantiene ante los cambios del sistema político y está preparado para cumplir sus objetivos. Los recursos presupuestarios y organizativos son un factor importante de este indicador, así como la sujeción a reglas procedimentales y sustanciales que diferencian a la institución de los individuos que coyunturalmente la personifican.

\section{IV.a. ¿Una nueva Corte Suprema?}

Dos son los hitos mediante los cuales la Corte Suprema se diferencia de su entorno: primero, al presentarse como una "nueva" Corte, distinta de la desprestigiada que vino a reemplazar; y segundo, al caracterizarse como un Tribunal "garante supremo de los Derechos Humanos" ${ }^{28}$. A principios del milenio el Tribunal había llegado a sus

${ }^{56}$ Kevin T. McGuire: "The Institutionalization of the U.S. Supreme Court", Political Analysis Vol. 12 Nro. 2 (2004), pp. 128-142.

${ }^{57}$ McGuire, ob. cit. en nota 81, p. 131.

${ }^{58}$ Cf. "F.A.L.", desarrollado supra en 3. a. iii) Autonomía individual vs 
mínimos históricos de legitimidad, luego de una década en la que sufrió un proceso de grave deslegitimación política ${ }^{59}$ y se produjo una profunda renovación. De ese modo, a fines del 2005, la "nueva" Corte Suprema se hallaba constituida y se enfrentaba al desafío de reconstruir su legitimidad y su perfil institucional. El recambio de miembros desprestigiados y acusados de no contar con los pergaminos para el cargo por candidatos de larga trayectoria académica y/o judicial supuso para el Tribunal una inyección de legitimidad de tipo carismática, no atribuible tanto a la institución en sí misma sino derivada de la legitimidad individual de sus nuevos miembros. La Corte pasaba a ser así una "Corte de notables". Esta renovación radical de sus miembros le permitió trazar una línea divisoria respecto del pasado, la misma que nos ha permitido a nosotros calificarla como una "nueva" Corte y a la nueva conformación oponer los cambios que iba proponiendo a las prácticas de la "vieja" Corte.

Con este capital inicial la Corte Suprema empezó su andadura, dejando entrever en algunas declaraciones y sentencias iniciales que tenía interés en marchar hacia un modelo semejante al de un Tribunal Constitucional ${ }^{60}$. Este curso de acción fue explicado por el Presidente de la Corte Suprema, Ricardo Luis Lorenzetti, en el discurso de Apertura del Año Judicial 2012, pronunciado el el 6 de marzo de ese año ${ }^{61}$. La Corte Suprema es presentada allí como la encargada de liderar una "transformación muy profunda, un cambio de modelo", cuyo objetivo central es la re-vinculación entre el Poder Judicial y la sociedad. Su función es "acercar la justicia a la gente, hacer hablar a la Constitución con la voz del pueblo de la Nación. Interpretarlo de modo que exprese

Derecho a la vida (F.A.L.); considerando 5 del voto de mayoría.

${ }^{59}$ Para una descripción de este proceso con mayor detalle, consultar Diana Kapiszewski: "La Corte Suprema y la Política Constitucional en la Argentina Post-Menem", Revista Jurídica de la Universidad de Palermo, Año 7 Nro. 1, 2006, pp. 5-46 y Valentín Thury Cornejo, ob. cit. en nota 5.

${ }^{60}$ Cf. Víctor Bazán, "¿La Corte Suprema de Justicia argentina se reinventa, presentándose como un Tribunal Constitucional?", Cuestiones Constitucionales (México), Nro. 20, 2009, en especial p. 20 y sigs.

${ }^{61}$ Desarrollamos estas ideas en el punto II de nuestro trabajo citado en nota 39. 
En el nombre del niño. El interés superior del menor en la construcción ...

las necesidades de nuestra gente". Se expresa así la necesidad de adquirir legitimación social que el Tribunal ve como un proceso inevitable de su reconstrucción institucional. Esta percibida necesidad de acercar la justicia a la gente, de hacer hablar a la Constitución con la voz del pueblo, supone -más allá de algunos instrumentos destinados a su escucha efectiva ${ }^{62}$ - la presencia de un intérprete privilegiado: la Corte Suprema de Justicia. Para eso, el primer paso es ampliar el acceso a la justicia: el Poder Judicial debe derribar las barreras de acceso e involucrarse en los conflictos que la sociedad le presenta. La Corte propone así una democratización de la Constitución a partir de la apertura de sus estrados a la voz de la sociedad.

Escuchar la voz de la gente y tamizarla a través de la interpretación constitucional es "hacer hablar a la Constitución con la voz del pueblo de la Nación". El corolario de esta postura es que el Tribunal se pone en un pie de igualdad con el resto de los poderes con legitimidad democrática directa y desde allí propone "un diálogo profundo con los demás poderes del Estado". De alguna manera, la Corte propone un camino paralelo al de los poderes políticos -Ejecutivo y Legislativo-, que en algún momento podrán cruzarse pero cuyo itinerario es independiente uno de otro. Como vemos, hay una relación directa entre la transformación de la administración de justicia que la Corte Suprema quiere liderar y la interpretación constitucional que propone en las sentencias que va enunciando. ¿El objetivo de la transformación pretendida? "Un Poder Judicial que afirme estos principios, que le diga a la Nación cuál es la Constitución actual, que le diga al pueblo cuáles son las grandes reglas de conducta, que le diga a todos cuáles son los principios que forman parte de nuestro contrato social, aquellos en los cuales tenemos

62 Dice Lorenzetti en una parte del discurso que "por eso hicimos las audiencias públicas, porque hemos entendido que la mejor manera de resolver estos conflictos es empezar a escuchar las distintas voces. Por esta razón también hemos tratado de expandir la legitimación...". Y continúa luego, diciendo: "es mucho mejor escuchar a la sociedad antes de tomar una decisión que tomarla pensando que uno tiene la razón de antemano, y es por eso que este debate público, institucional en las audiencias ha sido tan valioso para nosotros". 
que estar todos de acuerdo para que la sociedad sea viable...". Así, la Corte Suprema se entiende a sí misma y se presenta ante el resto de los poderes como "garante supremo de los derechos humanos".

\section{IV.b. ¿Construcción de corto o largo plazo?}

En este relato vemos, por partida doble, la institucionalización que intenta la Corte Suprema a través de su diferenciación respecto del resto de los poderes -tanto respecto de la pasada Corte como de los actores presentes- $\mathrm{y}$, concomitantemente, al afirmar su autonomía mediante el diseño de una agenda de actuación propia. En efecto, el Tribunal se encuentra, al acometer su tarea de refundación, con una legitimidad muy baja. Su alianza con la sociedad se inscribe en esta lógica. Pero ella tiene una consecuencia sumamente relevante, al alejarla de la disputa directa con los poderes políticos. En este sentido, la Corte Suprema ha intentado, en la medida de lo posible, seguir un camino autónomo, sin mayores interferencias de las ramas políticas. El Tribunal ha balanceado su actitud proactiva de fijación de agenda en temas socialmente relevantes con una deferencia hacia las iniciativas gubernamentales. Este equilibrio le ha permitido mostrarse autónoma e independiente, evitando conflictos políticos que pusieran en duda su estabilidad. De este modo, ha logrado construir legitimidad sin disputársela al resto de los actores políticos, estrategia fundamental en un contexto de escasa institucionalidad como el argentino ${ }^{63}$. La elección de los derechos como eje de su acción posee un atractivo comunicativo-retórico indudable y, al mismo tiempo, se sitúa en un terreno jurídico -el propio del Tribunal- pero de una flexibilidad tal que su inmersión en el terreno de las políticas públicas resulta altamente probable factible ${ }^{64}$. De este modo, la Corte está habilitada para con-

${ }^{63}$ Esta reticencia al enfrentamiento directo, utilizando a menudo términos vagos en sus pronunciamientos, es propio de tribunales sin un resguardo de legitimidad sólido (cf. Jeffrey K. Staton \& Georg Vanberg: "The Value of Vagueness: Delegation, Defiance, and Judicial Opinions", American Journal of Political Science, Vol. 52, No. 3 (Jul., 2008), pp. 515)

${ }^{64}$ Ello depende entre otras cuestiones de los cambios estructurales en el de- 
En el nombre del niño. El interés superior del menor en la construcción ...

seguir una alta exposición pública en su búsqueda de consenso social y así obtener legitimidad en ese terreno. No es de extrañar, por ello, el lugar relevante que la Corte Suprema le ha otorgado a su política comunicacional ${ }^{65}$.

El camino elegido por la Corte Suprema plantea desafíos importantes que están representados por las díadas "Derecho - Política" y "corto - largo plazo". Al asumir una posición autónoma frente a los otros poderes, el tribunal aplica formalmente el derecho pero lo hace del mismo modo en que lo realizan los poderes políticos. Tradicionalmente limitada a un papel revisor de las decisiones de los otros actores políticos que ponen en marcha e implementan los designios constitucionales, al asumir directamente una función de ese tipo, la línea divisoria entre Derecho y Política queda muy desdibujada y de ello da cuenta el uso de instrumentos jurídicos novedosos, tanto en lo procedimental como en lo sustantivo. La Corte no se siente limitada por el Derecho existente, tal como ha sido establecido por las ramas políticas, sino que entiende que su función constitucional la obliga a -en ocasiones- trascenderlo. Esto le genera un problema en el largo plazo, ya que para seguir estando legitimada en cuanto aplicadora del Derecho -o sea, como actor jurídico-deberá someterse a reglas. Al producir un corte en la cadena de legitimación y postularse como

recho que, conllevan, cambios en las facultades de los jueces. El derecho actual en este sentido difumina los anteriormente nítidos límites entre Derecho y Política. Entre los procesos que acentúan la discrecionalidad interpretativa del juez constitucional se cuentan la constitucionalización del Derecho infra-constitucional, la proliferación de normas programáticas y de contenido difuso y la creciente relevancia de nuevos instrumentos de acceso a la justicia constitucional -amparos, medidas cautelares, acciones de clase, etc.- (cf. Gustavo Zagrebelsky, El derecho dúctil. Ley, derechos, justicia, Ed. Trotta, Madrid, 1997 ( $2^{\circ}$ ed.).

${ }^{65}$ Opuesta a la anterior cultura del sigilo y del secreto judicial, el Tribunal ha adoptado, frente a su tradicional posición pasiva, una actitud proactiva respecto de la comunicación. Su Presidente, Ricardo L. Lorenzetti, la ha explicado con cierto detalle en este documento: Politicas de Estado para el Poder Judicial, discurso pronunciado en la Segunda Conferencia Nacional de Jueces, Salta, Argentina, 2007. 
una "nueva" Corte Suprema, el tribunal plantea una disrupción en la durabilidad institucional. Su "refundación", sin dudas requerida por las circunstancias históricas, implica darse nuevas normas de funcionamiento y adoptar perspectivas diferentes sobre los problemas. Pero desde el punto de vista de la durabilidad, este momento de cambio debe, necesariamente, estabilizarse, lo cual supone dejar de lado cuotas de poder actual -discrecionalidad en las decisiones- para ganar legitimidad en el mediano largo -a través de la estabilidad institucional- ${ }^{66}$.

\section{IV.c. E1 Interés Superior del Niño como concepto bisagra}

La jurisprudencia de la Corte Suprema de Justicia respecto del Interés Superior del Niño se enmarca en el complejo proceso que acabamos de analizar. La construcción de identidad de la Corte Suprema como un tribunal de garantía de los derechos humanos, con políticas activas de protección de los derechos, creatividad judicial y necesidad de reconstruir su legitimidad en el corto plazo explican muchos de los trazos que mencionamos en el análisis de su labor en el año 2012/3. La mención jurisprudencial del principio del Interés Superior del Niño es, en sí mismo, un acto retórico de enorme potencia comunicativa y en el contexto de la creación de una nueva identidad adquiere sentido su utilización recurrente. En efecto, su uso otorga un plus de legitimidad que permite resolver -por vía principal o dando argumentos adicionales- cuestiones complejas como la obligatoriedad de vacunación o la revisión jurisdiccional de políticas públicas de vivienda. Por la negativa, es conveniente dejarlo de lado, a pesar de la obligatoriedad de su consideración de acuerdo con el artículo 3 de la

${ }^{66}$ Esto explica en el caso de EE.UU. la existencia de una legitimidad estable en la institución Corte Suprema, más allá de ocasionales sentencias controversiales con las que parte importante de la población no está de acuerdo. En estos casos, se discute "la" decisión pero no "el" derecho y legitimidad de la Corte Suprema para dictarla, lo cual asegura su cumplimiento (cf. Jeffrey J. Mondak \& Shannon Ishiyama Smithey: "The Dynamics of Public Support for the Supreme Court", The Journal of Politics Vol. 59, No. 4. (Nov. 1997), pp. 1114-1142). 
En el nombre del niño. El interés superior del menor en la construcción ...

Convención sobre los Derechos del Niño, cuando su potencial deslegitimador pudiera opacar la decisión tomada por la Corte Suprema. La argumentación seguida en el caso F.A.L. es, en nuestra opinión, claramente expresiva de esta dinámica y la falta de confronte de los derechos involucrados explica - por su ausencia- el valor comunicativo que el Tribunal otorga al principio.

Forjar esta nueva identidad como intenta la Corte Suprema requiere de actos que la constituyan, a través de la defensa -y comunicación de esa defensa- de los derechos constitucionales que la Corte apuntala en sus sentencias. Pero, para poder llevar a cabo esta política, el Tribunal debe poseer la capacidad de actuar por sí misma, sobrepasando en ocasiones los límites que los modos institucionalizados de producción del Derecho imponen. En el plano sustancial, ello va a significar la posibilidad de leer el ordenamiento jurídico desde la perspectiva del derecho que quiere reforzar y trascender sus "rigideces". En el plano procedimental, deberá tener la capacidad de ampliar su competencia jurisdiccional para tener la oportunidad de dictar sentencia en los casos en los que se los propone. El caso de la adopción post mortem -analizado más arriba-, ejemplifica de modo adecuado estas dos características y así vemos a una Corte activa, protagonista y creativa, lejos de la auto-restricción. El interés superior del niño legitima así las capacidades decisorias que el Tribunal asume. Distinto pareciera ser el criterio seguido cuando esas competencias se ponen en juego, por ejemplo, cuando se trata de seguir la voz del niño ${ }^{67}$. En efecto, escuchar al niño supone transferir el locus de la decisión del juez -hasta ese momento máximo intérprete de su interés- hacia el menor -que no decide, propiamente, pero debe ser activamente escuchado-. Esta

${ }^{67}$ Son paradigmáticos, en este sentido, los casos en los que Corte Suprema resuelve controversias referentes a la aplicación de la Convención de La Haya de 1980 sobre Restitución Internacional de Menores los que ameritarían un análisis que las restricciones de espacio no nos permite aquí. Durante el período en análisis, la Corte Suprema se ha pronunciado en "G., P. C. c/H., S. M. s/reintegro de hijo", del 22 de agosto de 2012, "AHC c/ JAMA s/ restitución internacional de menor", del 21 de febrero de 2013 y "F., C. del C. cl G., R. T. s/ reintegro de hijo", del 21 de mayo de 2013. 
lógica explicaría la paradoja de una Corte sumamente expansiva en la consideración del ordenamiento cuando la interpretación del interés del niño queda en su ámbito, pero restrictiva cuando se trata de delegarlo e instrumentar nuevas formas de participación -sea a nivel general o en la escucha y acogimiento concreto de la voz del menor- ${ }^{68}$.

Las características estructurales del principio del interés superior del niño lo hacen especialmente adecuado para expresar las tensiones del proceso de legitimación de la Corte Suprema, entre ellas, la referida a la falta de desarrollo jurídico del concepto. Las menciones que en sus sentencias hace el tribunal son de una vaguedad tal, que remiten a su fuerza retórica antes que a la construcción de un principio operacionalizable. Hemos notado, en este sentido, la falta de referencia a los documentos interpretativos del Comité sobre los Derechos del Niño sobre el derecho que tiene el niño a ser escuchado. Respecto de las importantes sentencias de la Corte Interamericana, la utilización que hace la Corte Suprema es elocuente. En el caso de la adopción post mortem, por ejemplo, el tribunal menciona específicamente el caso Fornerón, cita su caracterización general del principio, su defensa del derecho a la identidad del menor pero no aplica ni desarrolla la solución concreta que ese Tribunal dio al caso. De este modo, toma del principio su potencial legitimador y la resta su faceta restrictiva, no fijando ni creando reglas para su utilización futura -ni para él, ni para los jueces inferiores-. El interés superior del niño queda indefinido en su contenido sustancial y funciona, a estos efectos, como una mera norma de atribución de competencia decisional de carácter discrecional. La Corte Suprema será la que lo interpretará en cada concreto e irá así resolviendo las controversias, con todas las cartas en la mano. En este contexto, la falta de sistema tiene una lógica legitimatoria porque, en el corto plazo, le brinda al Tribunal herramientas decisionales. En el largo, sin embargo, la construcción jurídica será inevitable y eso, todavía, es una tarea pendiente.

${ }^{68}$ Cf. en este sentido, Valentín Thury Cornejo: “¿Escuchar al menor o solo oírlo?", en el blog jurídico Todo sobre la Corte (http://todosobrelacorte. com/2013/05/31/escuchar-al-menor-o-solo-oirlo/). 